\title{
Paradoxical embolism complicating massive pulmonary embolus
}

\author{
P.A.POOLE-W I L S N, A.R. L. MA Y, \\ and D. T A UBE
}

Intensive Care Unit and Department of Surgery, St. Thomas' Hospital, London SE1 7EH

\begin{abstract}
Poole-Wilson, P. A., May, A. R. L., and Taube, D. (1976). Thorax, 31, 354-355. Paradoxical embolism complicating massive pulmonary embolus. Paradoxical embolism is an unusual but well recognized complication of venous thromboembolic disease. This case report of a patient with massive pulmonary embolism, who had a paradoxical embolus through a patent foramen ovale, emphasizes that in these circumstances surgical intervention is indicated.
\end{abstract}

\section{CASE HISTORY}

A previously healthy 31-year-old man underwent left medial meniscectomy and made an uneventful recovery. At home, 16 days later, the left leg became painful and swollen, and, while being transported back to hospital, he developed acute dyspnoea and chest pain. On examination he was pale and sweating. The heart rate was $120 / \mathrm{min}$, blood pressure $90 / 60 \mathrm{mmHg}$, and respiratory rate $60 / \mathrm{min}$. The venous pressure was raised $5 \mathrm{~cm}$ above the sternal angle. A third heart sound was heard at the left sternal edge. No adventitial sounds were heard in the lungs. The left leg was swollen and tender, but the meniscectomy scar was well healed. The arterial $\mathrm{Po}_{2}$ breathing air was 56 $\mathrm{mmHg}$, the $\mathrm{PcO}_{2} 29 \mathrm{mmHg}$, and the $\mathrm{pH} 7 \cdot 42$. The electrocardiogram showed sinus rhythm with an S1, Q3, T3 pattern. The chest radiograph revealed prominence of the main pulmonary artery with pulmonary oligaemia. A clinical diagnosis of massive pulmonary embolism was made.

Bipedal phlebograms showed extensive thrombosis in the left leg and iliofemoral region. Pulmonary angiography demonstrated severe obstruction of all the pulmonary arteries except those to the left upper lobe. The pulmonary artery pressure was $37 / 5 \mathrm{mmHg}$. During this procedure the catheter passed across a patent foramen ovale.

Initial therapy with streptokinase was stopped after the patient had a haematemesis. Treatment was continued with heparin, 7500 units fourhourly, isoprenaline, $4.5 \mu \mathrm{g} / \mathrm{min}$, and oxygen. The right atrial pressure was raised to $10 \mathrm{~cm}$ above the sternal angle by infusion of plasma. Over the next 24 hours the patient's condition improvec but on the following day the left foot pulses bee came impalpable, and the left radial pulse was weak. Paradoxical embolism was considered possible diagnosis and the right atrial pressure was lowered to $7 \mathrm{~cm}$. Twelve hours later he suddenly became confused and dysarthric and developed right hemiplegia. He underwent pulmonary em bolectomy and closure of a $1 \mathrm{~cm}$ patent forame ovale on cardiopulmonary bypass. Postoperativel his haemodynamic condition improved, but ove $\overline{-}$ the next 48 hours he developed signs of increasing. intracranial pressure and died.

Necropsy confirmed the presence of thrombus in the left femoral vein and a small amount o $\varnothing$ residual clot in the pulmonary arteries. An ems

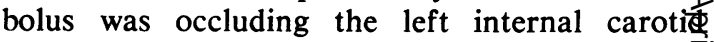
artery.

\section{DISCUSSION}

Paradoxical embolism was originally describe by Cohnheim in 1877 . At least 133 reports have since been documented in the literature and the association with massive pulmonary embolism common. There are only 17 reports in which the diagnosis has been made during life (Meister et al 1972; British Medical Journal, 1973), but this low figure may underestimate the true incidence.

The management of massive pulmonary em尺 bolism is controversial. At this hospital patien who do not require immediate pulmonary emp bolectomy are usually treated with anticoagulants 
or thrombolytic therapy and by elevation of the right atrial pressure to increase the cardiac output. If the condition occurs in a patient with a patent foramen ovale or an atrial septal defect, there exists a potential risk of paradoxical embolism as the right atrial pressure often exceeds that in the left atrium, and this reversal of the normal pressure gradient favours the development of a rightto-left shunt. Furthermore, artificially raising the right atrial pressure to improve the cardiac output will increase this risk. A patent foramen ovale is present in approximately $25 \%$ of the population. It may be argued, therefore, that if pulmonary angiography is undertaken to establish the diagnosis of pulmonary embolism, an attempt should be made to demonstrate the presence of a patent foramen ovale. This case clearly shows that, in the presence of a septal defect and a high right atrial pressure, conservative treatment of massive pulmonary embolism is contraindicated and that paradoxical embolism, if it occurs or is suspected, requires immediate surgical intervention. Procedures to prevent further emboli alone, such as inferior vena caval ligation, have the advantage that they are simple, but cardiopulmonary bypass permits both closure of the septal defect and removal of the circulatory obstruction.

We acknowledge the help of Professor N. L. Browse, Dr. B. S. Jenkins, and Mr. Bryn T. Williams for their permission to publish this case.

\section{REFERENCES}

British Medical Journal (1973). Paradoxical embolism. Editorial, 630.

Cohnheim, J. (1877). Thrombose und Embolie, in Vorlesungen über allgemeine Pathologie, Vol. 1, p. 134. Hirschwald, Berlin.

Meister, S. G., Grossman, W., Dexter, L., and Dalen, J. E. (1972). Paradoxical embolism: diagnosis during life. American Journal of Medicine, 53, 292.

Requests for reprints to: A. R. L. May, FRCS, Department of Surgery, St. Thomas' Hospital, London SE1 7EH. 